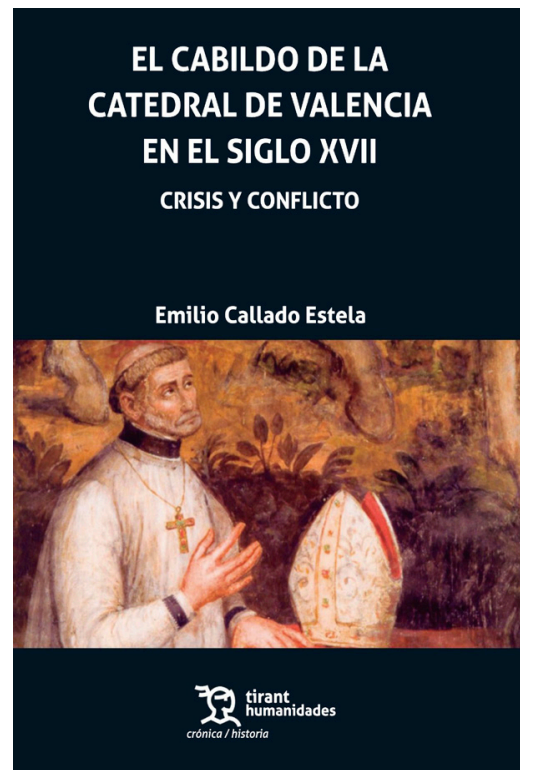

Ressenya a Callado, Emilio, El Cabildo de la Catedral de Valencta en el siglo XV II. Crisis y CONFLICTO, VALĖNCIA, ED. Tirant, 2019, 404 Pp., ISBN: 9788417508937

Review to Callado, Emilio, El Cabildo de la Catedral de V alencla en el siglo XVII. Crisis y CONFLICTO, VALÈNCIA, ED. Tirant, 2019, 404 Pp., ISBN: 9788417508937

\title{
Alfonso Esponera
}

Facultad de Teología de València

El profesor Emilio Callado Estela desde el año 1998 viene enriqueciendo sobre manera la historia eclesial y eclesiástica - de claras manifestaciones sociales y económicas- del antiguo reino de Valencia, fundamentalmente de los siglos XVI y XVII, de los que es un gran especialista. Así lo confirman sus muchos e interesantes trabajos, sobre hechos y personajes desconocidos o que han completado y matizado otros ignorados en parte o totalmente. En esta ocasión, profundiza en una de las instituciones locales de mayor importancia y trascendencia del pasado valenciano: el Cabildo de la Catedral de Valencia durante la decimoséptima centuria.

Las instituciones capitulares suponían hasta hace bien poco un vacío historiográfico imperdonable, pese a su constitución como centro de poder y no sólo eclesiástico, como lo fueron todos los capítulos catedralicios coetáneos. Su libro, con un sugerente prólogo del gran maestro M. Barrio 
Gozalo, de la Universidad de Valladolid, ofrece tres partes de acertada elección, precedidas por una muy pertinente introducción (pp. 17-26), donde se traza el estado de la cuestión de los estudios sobre cabildos hispánicos en general y valenciano en particular. En la primera de estas partes (pp. 31-150), nuestro autor profundiza con el escalpelo que caracteriza toda su obra la evolución cronológica de las relaciones episcopocapitulares a lo largo del Seiscientos: tiempos del santo Patriarca Ribera, del polémico padre Isidoro Aliaga, del inflexible Luis Alfonso de Los Cameros y del dominico fray Juan Tomás de Rocabertí. En la segunda parte (pp. 153-257), se centra en los conflictos suscitados a nivel interno entre los diferentes cuerpos de prebendados que conformaban el capítulo metropolitano valentino, es decir canónigos, dignidades y pavordes, o lo que es lo mismo, las ambiciones de los dos últimos sobre la hegemonía ejercida por el primero intramuros de la seo. La tercera parte está conformada por un apéndice documental (pp. 261-319) que consta a su vez de dos apartados, a cual de ellos más gratificante. Por un lado, una excelente selección de textos que ilustran con pormenor cuanto se ha dicho en las páginas previas. Y del otro, un prolijo catálogo alfabético de prebendados catedralicios (pp. 321-384) -con sus respectivos cursus honorum y obra escrita- que componen la mejor de las prosopografías existentes a día de hoy sobre tal asunto. Se cierra el volumen con la exposición del abrumador elenco de fuentes (manuscritas e impresas) (pp. 387-390) a las que el Profesor Callado nos tiene acostumbrados en todos sus estudios; más una cuida bibliografía muy útil (pp. 391-400).

El lector, en fin, se encontrará ante un estudio histórico de fuste elaborado a partir de un método riguroso, lejos del ensayismo fácil, de las afirmaciones gratuitas, de las hipótesis aventuradas o las apologías cómodas que las instituciones de este tipo han venido teniendo en la historiografía más tradicional. Se sujeta a las fuentes que conoce y domina, brindando siempre la correspondiente apoyatura documental. Estamos ante una investigación que ofrece una información densa, pero de ideas claras y de elegante hechura. Absolutamente recomendable, pues. 